\title{
Pedicled and Perforator Flaps in Reconstrucion of Post Trauma Defects in Upper Limbs.
}

\author{
Nardi Kola1, Sokol Isaraj' ${ }^{1}$, Gezim Xhepa ${ }^{1}$ \\ https://doi.org/10.32391/ajtes.v3i2.54
}

\begin{abstract}
Background: Upper extremity soft tissue reconstruction is an extensive topic as a multitude of options exist for diverse soft tissue defects involving shoulder, arm, elbow, forearm, wrist, and hand. Many of the times flap cover is necessary for resurfacing exposed critical structures like tendons, neurovascular structures, bone and to provide supple tissue over joints. Pedicled and perforator flaps are seen in last years as a good choice to restore length, sensitivity and function of the injured upper limb.

The aim of this paper is to give an overview of the definitions of as well as to present our experience regarding pedicled and perforator flaps.

Materials and methods: A retrospective analysis of 15 trauma patients who underwent pedicled and perforator flaps during the 2012-2016 timeframe period was made. The patients were divided according to their type of injury, as well as the types of flasp that were used.

Results: We have performed in total: 7 Foucher's flaps, 4 Posterior Interosseous Artery flaps, 1 Radial Recurrent Artery flap, 1 Quaba flap, 1 SDMA flap. We had only two cases of partial necrosis of the flaps and all the others survived completely.

Conclusions: Every single flap elevated successfully is linked with a meticulous surgical technique. We should take a special care in pedicle positioning because pedicle strangling was the most important negative factor in our two flap partial necrosis. Understanding the mistakes will help us to improve our surgical techniques day after day.

Keywords: post-trauma defect, reconstruction, pedicled flaps, perforator flaps
\end{abstract}

*Corresponding Author: Nardi Kola

$=凶 E$-mail: $\underline{\text { nardikola@yahoo.co.uk }}$

${ }^{1}$ Service of Burns and Plastic Surgery UHC Mother Teresa 


\section{Full Text}

\section{Introduction}

Upper extremity soft tissue reconstruction is an extensive topic as a multitude of options exist for diverse soft tissue defects involving shoulder, arm, elbow, forearm, wrist, and hand.

Many of the times flap cover is necessary for resurfacing exposed critical structures like tendons, neurovascular structures, bone and to provide supple tissue over joints.

The options include local, regional, distant and free flaps. It is well established that free flap option is a versatile single stage procedure facilitating simultaneous reconstruction of other critical structures. It also allows post-operative mobilization and early discharge and return to work. On the other hand, it requires additional resources, workforce, prolonged operating time and carries a risk of total loss of flap.

Pedicled flaps have been the workhorse flaps for reconstruction of the upper limb in many centers across the world. Though the procedure includes multiple surgery, prolonged immobilization, and joint stiffness, refinements in the execution of flap can prevent many of the disadvantages. In some aspects, the outcome is better than free flap reconstruction.

Pedicled and perforator flaps are seen in last years as a good choice to restore length, sensitivity and function of the injured upper limb. ${ }^{15}$
To be successful in such complicated procedures we should be aware of:

1-Careful planning of the most effective flap in the area involved

2-Careful selection of the patient [age, diseases, drug and alcohol abuse]

3-When is possible we can identify the perforator vessel or the artery of the supposed pedicle using a hand Doppler

4-In some cases an Angiography is important 5-The consent of the patient is extremely important 4,5

\section{Pedicled and Perforator Flaps}

A pedicle flap is a tissue transfer nourished by a well-defined longitudinal vascular pedicle.

A perforator flap can be strictly defined as a tissue transfer nourished by a myocutaneous perforator.

A perforator flap is named after the nutrient artery or vessels and not after the underlying muscle. If there is a potential to harvest multiple perforator flaps from one vessel, the name of each flap should be based on its anatomical region or muscle.

Practically the perforator flap technique has expanded to any perforator to the skin, including myocutaneous and septocutaneous vessels ${ }^{1,2,3}$.

\section{Materials and Methods}

A retrospective analysis of 15 trauma patients who underwent pedicled and perforator flaps during the 2012-2016 timeframe period was made. The patients were divided according to their type of injury, as well as the types of flasp 
that were used. We have measured pedicle length and main artery diameter using a Castro-Vievo caliper. Flap survial, flap sensitivity, donor site sensitivity, patient satisfaction, smoking, alcohol abusing and bulky flap complication presence were followed up for a three months period of time. All pedicles were identified and measured. Hand Doppler was useful especially in perforator flaps.

\section{Results}

Out of 15 trauma patients in total, 7 of them were work injuries with bone or tendon exposure in upper limbs, 7 patients had injuries due to electrical burns treated before with escharectomies and 1 patient had a fire gun injury of the hand.
We have performed in total: 7 Foucher's flaps, 4 Posterior Interosseous Artery flaps, 1 Radial Recurrent Artery flap, 1 Quaba flap, 1 SDMA flap.

We had only two cases of partial necrosis of the flaps and all the others survived completely. The bulky flap complication and flap sensibility problems were the main concerns of our patients three months after the surgery.

\section{Types of flaps performed}

1-Second dorsal metacarpal artery flap

Flaps can be used proximally or distally based. The reliability of such a flap decreases from second to the fifth metacarpal bone regarding the frequency of presence of the DMAs. The pedicle length ranged from $5-7 \mathrm{~cm}^{6}$, 7. The procedure is depicted in the following images.
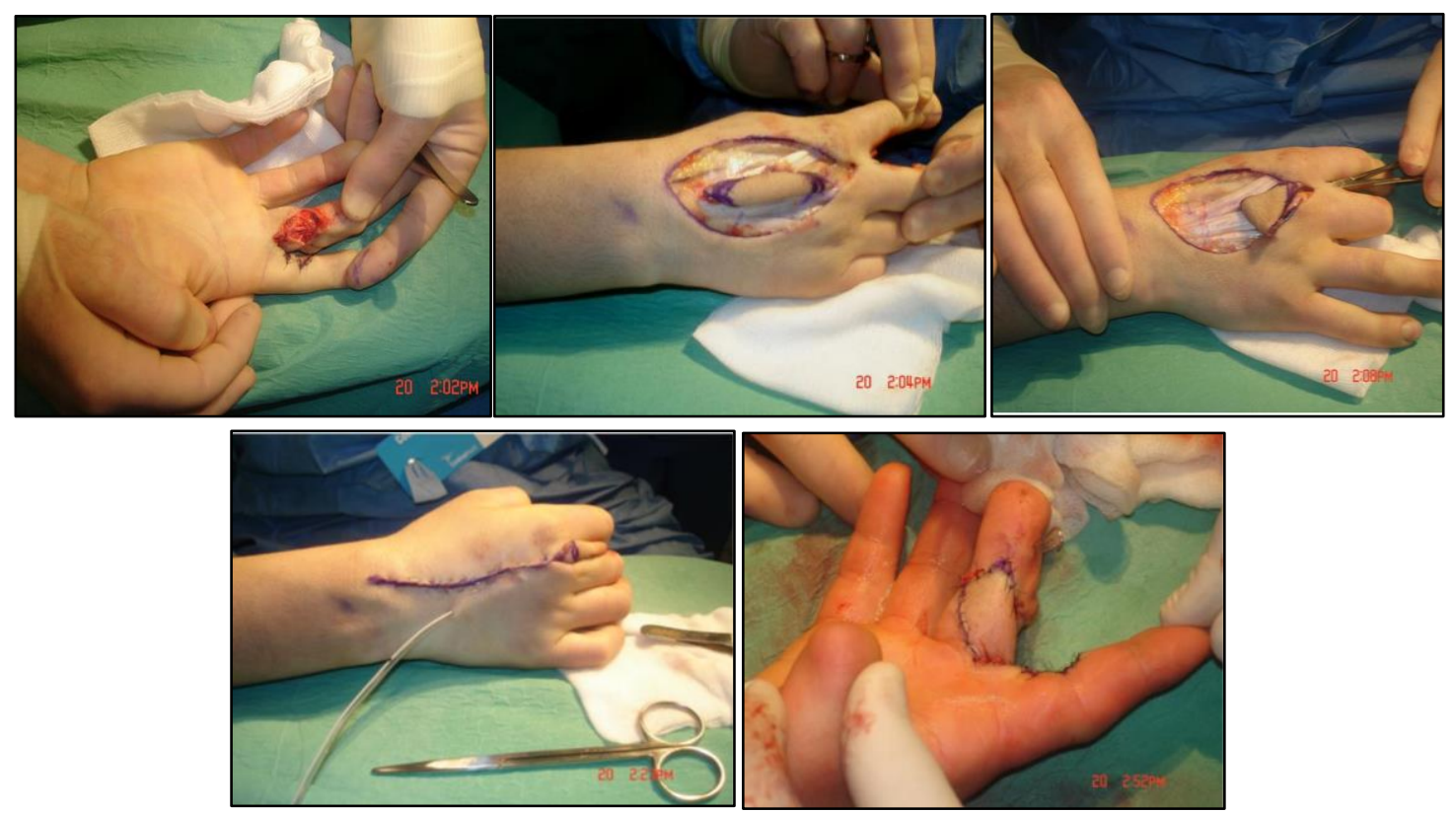

Figures 1-5: A work injury 


\section{2 - Foucher's Flap}

The outer diameter of the FDMA at its widest point is $1.0 \pm 1.5 \mathrm{~mm}$. In those without a palmar branch the diameter is less than $1 \mathrm{~mm}$. A muscular branch is present in $40 \%$. Flap pedicle is about $5-9$ $\mathrm{cm}$. The length of the flap ranged from 2$4 \mathrm{~cm}$. The flap width ranged from 1.5-2 $\mathrm{cm}$.
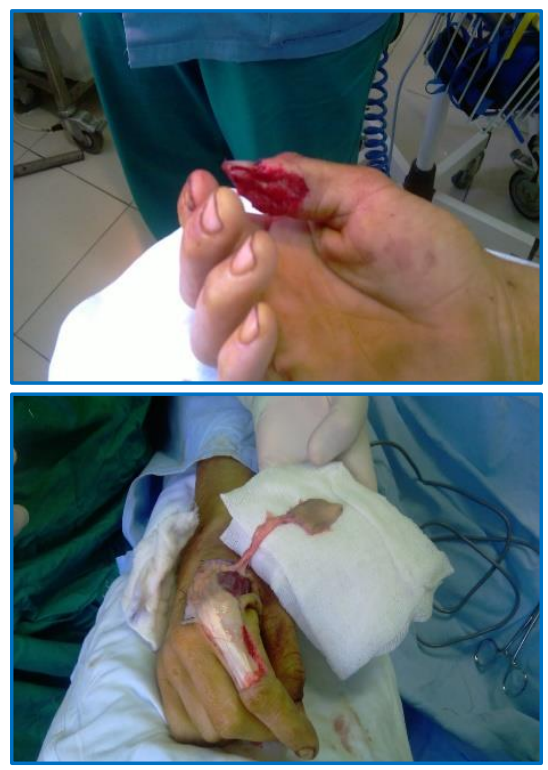

Figures 6-9: A work injury

3- PIA FLAP (posterior interosseous artery flap)

The PIA is located in the intermuscular septum between the extensor digiti minimi and extensor carpi ulnaris muscles. The artery gives off several fasciocutaneous perforators along its
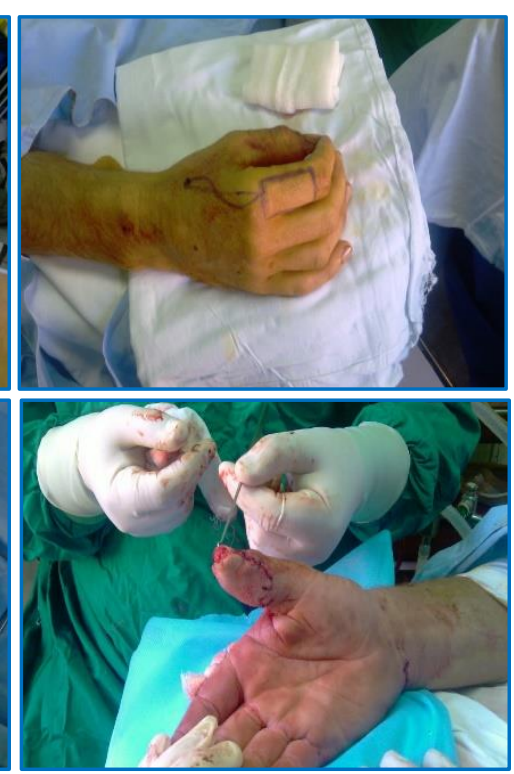

\section{Surgical Technique}

First, we did the flap painting in the dorsal part of the index finger above the proximal phalanx. We had to take care making the incision mainly in the radial part of the phalanx.

We raised the flap for security reasons in paratenon level because the artery in $43 \%$ of the cases run in subfascial plane. $12,13,14$ 


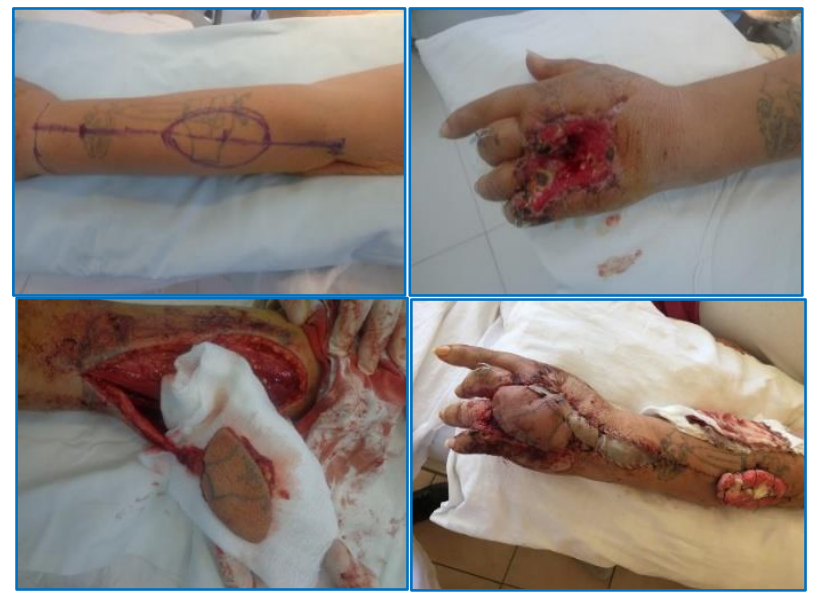

Figures 10-13: A gun injury

\section{4- Radial Recurrent Artery Flap}

The radial recurrent artery courses laterally and then upward along the medial surface of the brachioradialis, in a line between the brachialis and brachioradialis. This branch of the radial artery arises in the cubital fossa. Above the lateral epicondyle it forms an anastomosis with the radial collateral artery branches of the profunda brachi artery. 8,9

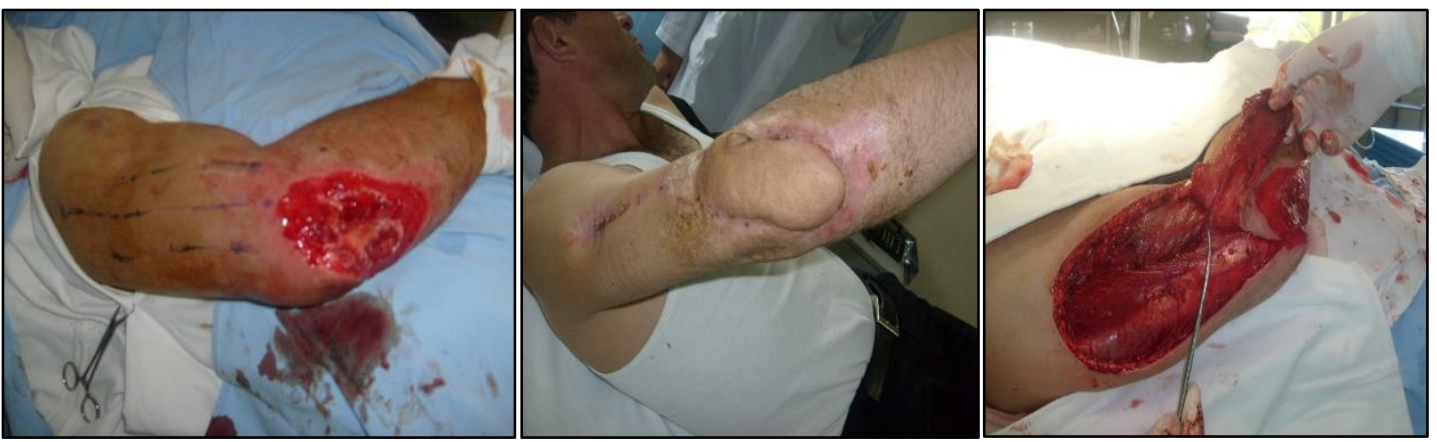

Figures 14-16: Electrical Burn

\section{Conclusions}

Every single flap elevated successfully is linked with a meticulous surgical technique.

We should take a special care in pedicle positioning because pedicle strangling was the most important negative factor in our two flap partial necrosis.

We have our failures too. Understanding the mistakes will help us to improve our surgical techniques day after day. 


\section{References}

1. Blondeel

PN,VanLanduyt,Monstry SJ,et

al.The Gent consensus on perforator flap terminology:preliminary definitions.PRS $112: 1378$ 1383:discussion 1384-1377,2003.

2. Cormack GC,Lamberty BG.Fasciocutaneous vessels.Their distribution on the trunk and limbs,and their clinikcal application in tissue transfer.Anat Clin 6:121-131,1984.

3. Hallock GG.Further clarification of the nomenclature for compound flaps.PRS

4. Hallock GG.Doppler sonografy and color duplex imaging for planning a perforator flap.Clin Plast Surg 30:347,2003.

5. Massia J,Clavero Ja,Larranga Jr, et al.Multidetector-row CT in the planning of abdominal perforator flaps.J Plast Recon Aesthet Surg 59:594.2006.

6. Geddes CR,Morris SF,Neligan PC.Perforator

flaps:evolution,classification and applications.Ann Plast Surg 50:90,2003.

7. Hwang K,Lee WJ,Jung CY,et al.Cutaneous perforators of the upper arm and clinical applications.J Reconstr Microsurg 21:463-469,2005.

8. The Functional Complex Anatomy of the Elbow: Jospt,www.jospt.org/doi/pdf/10 .2519/jospt.1993.17.6.279,by M Stroyan - 1993
9. Prantl L,Scherml S,Schwarce H,et al.A safe and simple technique using the distal pedicled reversed upper arm flap to cover large elbow defects.J Plast Reconstr Aesthet Surg 61:546-551,2008.

10. Agir H,Sen C,Alagoz S,et al.Distally based posterior interosseous flap:primary role in soft tissue reconstruction of the hand.Ann Plast Surg 59:291296,2007.

11. Cavadas PC,Ibanez J,Landin L,et al.Use of the reversed posterior interosseous flap in staged reconstruction of mutilating hand injuries before toe transfers.PRS 122:1823-1826,2008.

12. Chang SC,Chen SL,Chen TM,et al.Sensate first dorsal metacarpal artery flap fpr resurfacing extensive pulp defects of the thumb.Ann Plast Surg 53:449454,2004.

13. Eski M,Nisanci M,Sergenzer M.Correction of thumb deformities after burn:versatility of first dorsal metacarpal artery flap.Burns 33:65-71,2007.

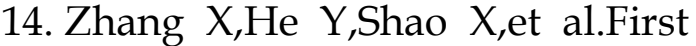
dorsal metacarpal artery flap from the dorsum of the middle finger for coverage of volar thumb defects.J Hand Surg Am 34:14671473,2009.

15. Reconstruction of post-traumatic upper extremity soft tissue defects with pedicled flaps: An algorithmic approach to clinical decision making: Chinese Journal of Traumatology Volume 21, Issue 6, December 2018, Pages 338-351 